\title{
Fluid balance in late preterm infants with prenatal gastrointestinal pathology -a report of two cases -
}

\author{
Byung Hoo Bahk and Hae Mi Lee \\ Department of Anesthesiology and Pain Medicine, School of Medicine, Yeungnam University, Daegu, Korea
}

Intestinal obstruction was diagnosed in two fetuses at maternal antenatal care. Both received emergency surgery on the day of their birth, at about 35 weeks gestational age. The disease progressed for a long time in both cases because prompt diagnosis and surgery are difficult to perform in utero. As a result, severe adhesion and distorted anatomy were observed in both cases. Massive third space losses and bleeding were predicted during the surgery. However, the accurate ongoing losses were difficult to anticipate. The assessment of fluid deficits cannot be based on measured losses alone, but hemodynamic status including blood pressure, heart rate, urine output, capillary refill, and/or central venous pressure should be evaluated additionally. (Korean J Anesthesiol 2013; 65: 456-461)

Key Words: Fluid therapy, Intestinal obstruction, Prenatal diagnosis.

In normal pregnancy, approximately $90 \%$ of newborn babies make the transition from intrauterine to extrauterine life without difficulty and $<1 \%$ need extensive resuscitative measures to survive [1]. Most of those who need resuscitation are preterms or babies with intrauterine abnormalities. Major abdominal surgery in a preterm infant is one of the most challenging tasks for an anesthesiologist. It requires not only manual skills for endotracheal intubation and insertion of venous and/or arterial lines, but also tight control of numerous hemodynamic parameters. Fluid challenging is the uppermost complicating problem, because a small volume loss can have significant effects on hemodynamic stability and the magnitude of volume loss is difficult to measure. Plasma volumes and the third space losses in a preterm infant are wholly different depending on their age and their pathologic conditions. Advanced cases of bowel obstruction frequently coupled with sepsis cause severe abdominal distension with intravascular volume depletion, acidosis, cardiovascular depression, and respiratory compromise. The consequence is the elevation of the diaphragm, which decreases functional residual capacity and results in alveolar closure during normal tidal breathing, leading to hypoxemia and respiratory failure in small infants $[2,3]$. Therefore, we should consider whether prompt intubation and mechanical ventilation is needed or not when fetal gastrointestinal pathology is anticipated.

Received: August 27, 2012. Revised: 1st, October 8, 2012; 2nd, October 9, 2012. Accepted: October 12, 2012.

Corresponding author: Hae Mi Lee, M.D., Department of Anesthesiology and Pain Medicine, School of Medicine, Yeungnam University, Daemyung 5-dong, Nam-gu, Daegu 705-717, Korea. Tel: 82-53-620-3361, Fax: 82-53-626-5275, E-mail: amy97@hanmail.net

(c) This is an open-access article distributed under the terms of the Creative Commons Attribution Non-Commercial License (http:// creativecommons.org/licenses/by-nc/3.0/), which permits unrestricted non-commercial use, distribution, and reproduction in any medium, provided the original work is properly cited. 
Transition from fetal to newborn life is associated with major changes in pulmonary, cardiovascular, renal system, and water/ electrolyte homeostatic control. In preterm infants, overhydration during the first week of life may induce patent ductus arteriosus (PDA), which is associated with the development of intraventricular hemorrhage, necrotizing enterocolitis, and bronchopulmonary dysplasia $[3,4]$. As newborns show a physiologically low glomerular filtration rate (GFR) and low urinary flow rate on the first day of life, they may be unable to increase water excretion and so can easily develop edema $[5,6]$. Therefore, tight control of volume is mandatory as well as glucose, electrolyte, acid-base status, urine output, oxygenation/ventilation, and temperature to premature infants with large fluid shift.

\section{Case Reports}

\section{Case 1}

A 31-year-old pregnant woman $(59 \mathrm{~kg} / 170 \mathrm{~cm}, 34 \mathrm{w}+5$, G4P2A1L2) was admitted for Caesarean section. The patient had no problems until fetal bowel obstruction was diagnosed by routine obstetrical ultrasonography taken 10 days earlier (Fig. 1).

General anesthesia was induced with $250 \mathrm{mg}$ of thiopental sodium and $75 \mathrm{mg}$ of succinylcholine. Ten minutes after skin incision, a $2.66 \mathrm{~kg}, 46 \mathrm{~cm}$ of male baby was born with an Apgar score of 7 at $1 \mathrm{~min}$ and 9 at $5 \mathrm{~min}$. The newborn cried relatively well despite the moderately distended abdomen, so routine care was given, which included transfer to the neonatal intensive care unit (NICU).

Peripheral oxygen saturation $\left(\mathrm{SpO}_{2}\right)$ of the baby was main-

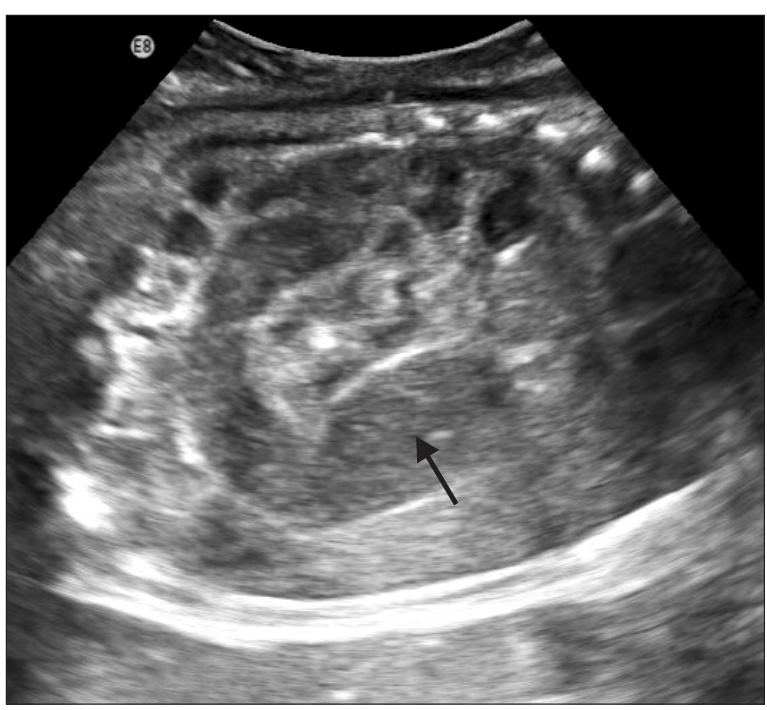

Fig. 1. Fetal ultrasonography of case 1 shows maximum $3 \mathrm{~cm}$ sized dilated bowel loops seen on right subhepatic area (arrow). tained at $96-97 \%$ with $2 \mathrm{~L} / \mathrm{min}$ of oxygen in the hood and first urine was passed at $4 \mathrm{~h}$ of age. However, abdominal distention was sustained and nothing was aspirated through the positioned oro-gastric tube. An infantogram, bowel sonography, and barium enema were performed. Distended small bowel loops up to $3 \mathrm{~cm}$ and microcolon were seen and no more contrast was passed proximal to terminal ileum, which suggested ileal atresia (Fig. 2).

Emergency surgery was performed at $10 \mathrm{~h}$ of age. Under standard monitoring including electrocardiography (ECG), non-invasive blood pressure (NIBP), end-tidal $\mathrm{CO}_{2}\left(\mathrm{ETCO}_{2}\right)$, and $\mathrm{SpO}_{2}$ (dual monitor at right arm and left foot), the patient was intubated with a 3.5 Fr cuffed endotracheal tube. Two 24 gauge intravenous (IV) lines were started on the left arm and right leg, a 6 Fr feeding tube was inserted for gastric decompression, and a Foley catheter was inserted for hourly urine count. To minimize heat loss, the room temperature was increased, the patient was hatted, a warm air mattress and warmed IV fluids were used, and body temperature was monitored. The anesthesia was maintained with sevoflurane, $\mathrm{FiO}_{2}$ of $0.3-0.4$ with air, pressure control mode of $18 \mathrm{mmHg}$, and a respiratory rate (RR) of 20 breaths $/ \mathrm{min}$. BP was maintained at $50-80 / 30-45 \mathrm{mmHg}$, heart rate (HR) at $140-160$ beats $/ \mathrm{min}, \mathrm{ETCO}_{2}$ at $32-40 \mathrm{mmHg}$, and $\mathrm{SpO}_{2}$ 98-100\%. There were severe adhesions on the entire abdomen such that the anatomy was not easily distinguishable. After massive adhesiolysis, segmental resection of injured bowel and anastomosis were performed. Moderate amount of reactive fluid was seen and moderate bleeding was ongoing. At 90 min of the surgery, HR abruptly rose to 170 beats/min. Arterial

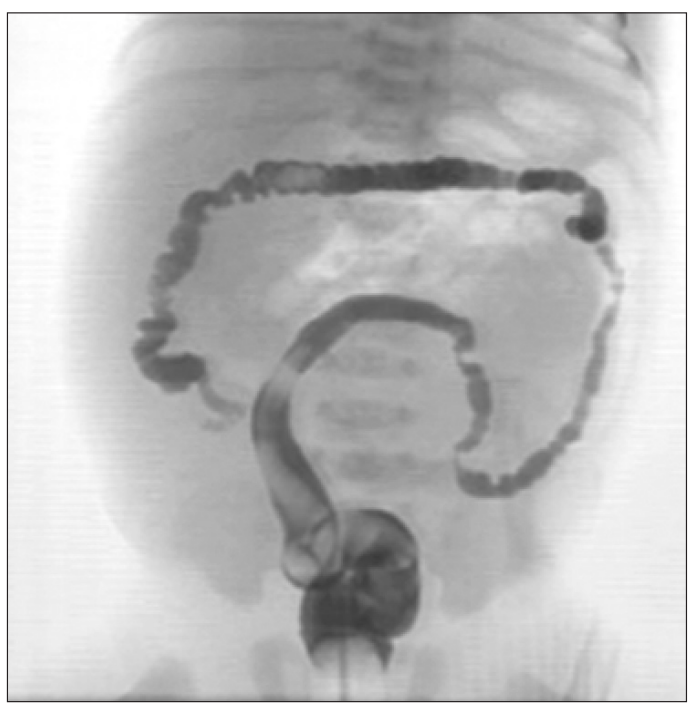

Fig. 2. Preoperative barium enema of case 1 shows diffuse luminal narrowing suggesting microcolon on retrograde filling of larger bowel. Contrast advanced into the terminal ileum but no more passsage is seen proximal to terminal ileum. 
blood gas analysis was taken, which showed $\mathrm{pH}$ 7.34, $\mathrm{PaCO}_{2} 38$ $\mathrm{mmHg}, \mathrm{PaO}_{2} 191 \mathrm{mmHg}, \mathrm{HCO}_{3} 20.5 \mathrm{mM} / \mathrm{L}, \mathrm{Na} 134 \mathrm{mEq} / \mathrm{L}$, $\mathrm{K} 4.2 \mathrm{mEq} / \mathrm{L}$, Hb $10.2 \mathrm{~g} / \mathrm{dl}$, and blood sugar $118 \mathrm{mg} / \mathrm{dl}$. Packed red blood cells $30 \mathrm{ml}$ were transfused and no other intraoperative symptoms were found. Total time taken for surgery was $2 \mathrm{~h}$ $45 \mathrm{~min}$ and for anesthesia, $3 \mathrm{~h} 20 \mathrm{~min}$. Total fluid administered was SD $1: 3$ solution $20 \mathrm{ml}$, lactated Ringer's solution $50 \mathrm{ml}$, and normal saline $10 \mathrm{ml}$.

After the surgery, the patient was extubated and $\mathrm{SpO}_{2}$ was maintained over $97 \%$ without supplemental oxygen. Urine output was $1 \mathrm{ml} / \mathrm{h}$ and $1.5 \mathrm{ml} / \mathrm{h}$, respectively, during the first $2 \mathrm{~h}$ of surgery, however, no further urine was observed during last hour of surgery. However, $7 \mathrm{ml}$ of urine was formed after $2 \mathrm{~h}$ of surgery without fluid loading and no further oliguria was seen. $\mathrm{Hb}$ after transfusion was $13.6 \mathrm{~g} / \mathrm{dl}$ and hemodynamic parameters were stable thereafter. Breast feeding was started 5 days after the surgery and the baby was discharged at postoperative day 24 .

\section{Case 2}

A 29-year-old, pregnant woman $(70 \mathrm{~kg} / 169 \mathrm{~cm}, 29 \mathrm{w}+5$, G1P0A0L0) was transferred from outlying hospital for polyhydroamnios with fetal abdominal mass. On obstetrical ultrasonography and magnetic resonance image, a cystic mass about 8.5 $\times 7 \mathrm{~cm}$ in size was observed in the fetal peritoneal cavity (Fig. 3 and 4). On the decision that the baby required more maturation, surgery was postponed until gestational age 35 weeks with steroid therapy and follow-up sonography. At 35 weeks, two operating theaters were prepared for surgery for both mother and the baby.

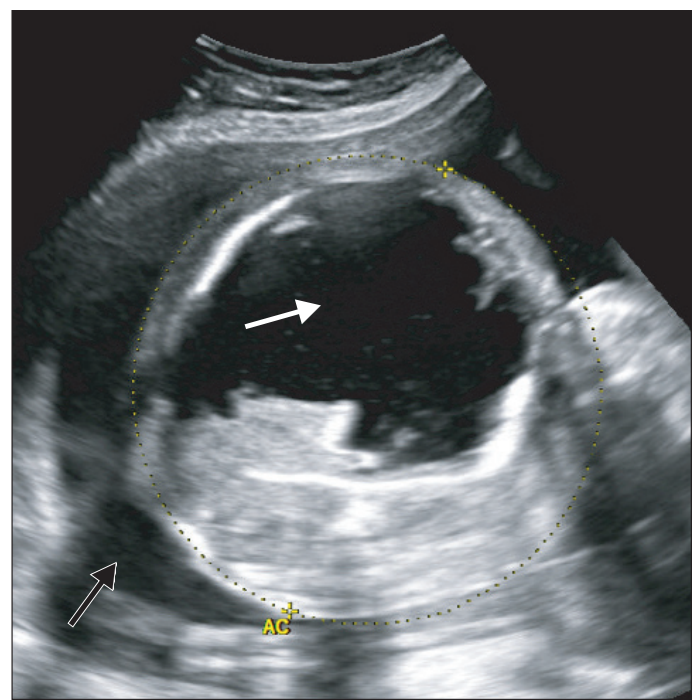

Fig. 3. Polyhydroamnios (black arrow) noted on fetal ultrasonography of case 2 . A cystic lesion about $8.5 \times 7 \mathrm{~cm}$ is size (white arrow) was observed in the fetal abdomen.
General anesthesia for Caesarean section was induced with $250 \mathrm{mg}$ of thiopental sodium and $75 \mathrm{mg}$ of succinylcholine. Ten minutes after skin incision, a profuse amount of meconium stained amniotic fluid was released and an approximately $2.5 \mathrm{~kg}$ male baby was delivered. Apgar scores were 5 at $1 \mathrm{~min}$ and 7 at 5 min. The baby's abdomen was markedly distended (Fig. 5) and meconium stained secretion continuously flowed from the nose and mouth. After suction of the airway, intubation was tried with 3.5 Fr cuffed endotracheal tube. This failed, so a 3.0 Fr tube was inserted in the second attempt. A pulse oximeter was attached on the baby's right hand and left leg, which showed $97 \%$ with $100 \%$ oxygen after resuscitation. Two 24 gauge IV lines were started both on the right arm and right leg. A 6 Fr feeding tube was inserted for gastric decompression. We requested Foley catheter insertion. However, it was not performed. Anesthesia was maintained with sevoflurane and $\mathrm{FiO}_{2}$ of $0.3-0.4$ with air

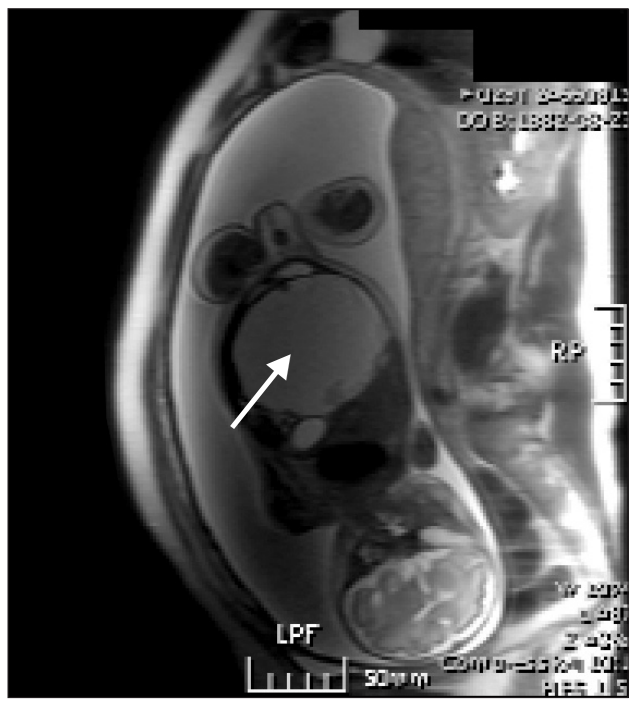

Fig. 4. Sagittal T2 weighted magnetic resonance image of case 2 revealing cystic mass in the intrauterine fetal abdomen (arrow).

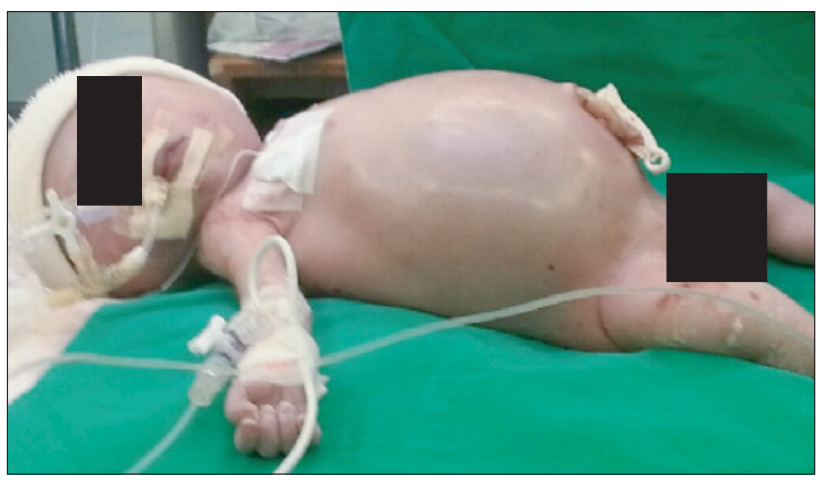

Fig. 5. A gross picture of case 2 . A baby about $2.5 \mathrm{~kg}$ in weight male was born with marked abdominal distention due to a huge intraabdominal cyst. 
under standard monitoring and temperature devices similar to setting of case 1 . The ventilator was set by pressure control mode of $24 \mathrm{mmHg}$ (TV near $25 \mathrm{ml}$ ) and RR of 30 breaths/min, however, $\mathrm{SpO}_{2}$ dropped and was maintained around $70 \%$. Therefore, $\mathrm{FiO}_{2}$ was increased up to 1.0. However, $\mathrm{SpO}_{2}$ did not change so manual ventilation was applied with $100 \%$ oxygen for about 40 min until the abdomen opened and the cyst was evacuated. $\mathrm{SpO}_{2}$ was maintained at $90 \%$ during that period and, just after cyst evacuation, it abruptly increased to $98 \%$, so the $\mathrm{FiO}_{2}$ was decreased to 0.3 . The ventilator was set by a pressure control mode of $18 \mathrm{mmHg}$ (TV near $30 \mathrm{ml}$ ), 25 breaths/min, and controlled according to the $\mathrm{ETCO}_{2}$ level. BP was maintained at $40-$ 60/25-35 mmHg, HR at 130-160 beats/min, $\mathrm{ETCO}_{2}$ at 27-35 $\mathrm{mmHg}$, and $\mathrm{SpO}_{2}$ at $97-100 \%$.

Surgery was complicated by lots of bowel manipulations. Severe adhesion to omentum, liver, and small bowel was seen and moderate ascites were found. After adhesiolysis, the cyst was removed and end-to-end anastomosis of the small bowel was performed. Total time taken for the surgery was $3 \mathrm{~h} 30 \mathrm{~min}$ and for anesthesia, $4 \mathrm{~h} 10 \mathrm{~min}$. Total fluid administered was 5\% dextrose in water $\left(\mathrm{D}_{5} \mathrm{~W}\right) 35 \mathrm{ml}$ and lactated Ringer's solution $130 \mathrm{ml}$. After $120 \mathrm{~min}$ of anesthetic induction, venous blood gas analysis was taken, which showed $\mathrm{pH} 7.29, \mathrm{PaCO}_{2} 44 \mathrm{mmHg}$, $\mathrm{PvO}_{2} 34 \mathrm{mmHg}, \mathrm{HCO}_{3} 21.2 \mathrm{mM} / \mathrm{L}, \mathrm{Na} 133 \mathrm{mEq} / \mathrm{L}, \mathrm{K} 3.7 \mathrm{mEq} / \mathrm{L}$, $\mathrm{Hb} 18.7 \mathrm{~g} / \mathrm{dl}$, and blood sugar $121 \mathrm{mg} / \mathrm{dl}$.

Just after the surgery, we looked for evidence of urination on drape linen, but it was dry. The baby was sent to the NICU with a secured ET tube with manual assisted ventilation. Foley catheterization was done at the NICU and urine output was very poor after the surgery. Dopamin $5 \mu \mathrm{g} / \mathrm{kg} / \mathrm{min}$ was infused with normal saline $60 \mathrm{ml}$, fresh frozen plasma (FFP) $40 \mathrm{ml}$, and 20\% albumin $13 \mathrm{ml}$ over $6 \mathrm{~h}$. Furosemide $4 \mathrm{mg}$ was IV injected two times during hydration period, however, only $4 \mathrm{ml}$ of urine was formed. Generalized edema appeared with heart murmur, but urine starting to pass at $10-20 \mathrm{ml} / \mathrm{h}$ at the same time. The baby was extubated $20 \mathrm{~h}$ after the surgery and $\mathrm{SpO}_{2}$ was maintained over $95 \%$ without supplemental oxygen. Feeding was started 8 days after the surgery.

\section{Discussion}

Intraoperative fluids are administered by a guide consisting of replacement of preoperative deficit, maintenance, third space loss, and bleeding. Dextrose solution is used for maintenance therapy and isotonic, non-glucose-containing solution for ongoing losses. Although the common rule for hourly water requirement is well-known (the $4-2-1$ rule), $4 \mathrm{ml} / \mathrm{kg} / \mathrm{h}$ for immediate newborn seems to be slightly too much, because they can be born with excessive extended-care facility (ECF) and their urine output can be very poor at 1-2 days of age. Therefore, it can be subdivided into $2 \mathrm{ml} / \mathrm{kg} / \mathrm{h}$ for day $1,3 \mathrm{ml} / \mathrm{kg} / \mathrm{h}$ for day 2 , and $4 \mathrm{ml} / \mathrm{kg} / \mathrm{h}$ for day 3 onward [5]. $\mathrm{D}_{5} \mathrm{~W}$ may be used for maintenance solution, however, care should be taken because hyponatremia may develop due to its hypotonic nature and newborns in the first day of life usually have poor urine output. Also, tighter blood sugar analysis is required because hyperglycemia is prone to occur [7]. Instead of $\mathrm{D}_{5} \mathrm{~W}$, Murat and Dubois [8] recommended 1-2\% dextrose solution, which is sufficient to maintain an acceptable blood glucose level. In our second case, in which $\mathrm{D}_{5} \mathrm{~W}$ was used, blood sugar was $69 \mathrm{mg} / \mathrm{dl}$ at age of 90 $\mathrm{min}$, but rose to $121 \mathrm{mg} / \mathrm{dl}$ only after $100 \mathrm{~min}$.

Generally, sodium supplementation is not required for the first $24 \mathrm{~h}$. However, neonates should be given IV fluids which contain sodium when hyponatremia exists or extracellular fluid volume loss exceeds $5 \%$ of body weight per day [2]. Traditionally, potassium is not given to the babies who do not urinate. Although we were not sure whether the baby had urinated, lactated Ringer's solution was infused in the second case because a large volume of normal saline may induce metabolic acidosis. Fortunately, serum sodium and potassium were in acceptable range at $3 \mathrm{~h}$ of age (133 and $3.7 \mathrm{mEq} / \mathrm{L}$, respectively).

Preterm babies have a blood volume of $90-100 \mathrm{ml} / \mathrm{kg}$ and term babies have $80-90 \mathrm{ml} / \mathrm{kg}$ at delivery [9]. The majority of volume loss during abdominal surgery is due to bleeding and third spacing. Bleeding can be measured by weighing sponges, observing small calibrated suction bottles, and visual estimation [10]. However, estimation with small infants is very difficult. The third space loss may vary from $1 \mathrm{ml} / \mathrm{kg} / \mathrm{h}$ for a minor surgery to as much as $15-20 \mathrm{ml} / \mathrm{kg} / \mathrm{h}$ for major abdominal surgery, or even up to $50 \mathrm{ml} / \mathrm{kg} / \mathrm{h}$ for necrotizing enterocolitis in premature infants [10]. Since the fluid loss into the third space is due to capillary leakage into tissues, the electrolyte and protein concentration of this fluid are similar to plasma [2]. Therefore, balanced salt solutions such as lactated Ringer's or normal saline are recommended as the first choice because they are effective, inexpensive, free of coagulation abnormality, anaphylaxis, and infection. Albumin or other colloid solutions are rarely used and are indicated after administration of $30-50 \mathrm{ml} / \mathrm{kg}$ of crystalloid solution [10].

If the serum protein concentration is low, albumin may be used. Large amount of lactated Ringer's solution is associated with a decreased serum osmolality and development of edema due to its slightly hypotonic nature, while normal saline is associated with development of dilutional or hyperchloremic acidosis [3]. Other synthetic colloids may be used. However, the number of pediatric studies aimed at evaluating its efficacy and tolerance are limited [10]. In the case of massive third space losses in a preterm baby, intraoperative use of colloid solutions could be better than crystalloids because preterm babies have low serum albumin concentrations and reduced plasma oncotic 
pressure [6]. Although albumin maintains the colloid osmotic pressure, there are no proven benefits to its use $[11,12]$. There is no evidence that albumin administration reduces mortality in critically ill patients with hypovolemia, burns, or even with hypoalbuminemia [13]. A subgroup analysis showed there were no significant differences in outcomes between albumin and saline. Instead, albumin had a higher mortality rate opposed to saline in adult traumatic brain injury patients [14]. Albumin is also associated with development of hypernatremia and chronic lung disease $[3,15]$, and when it is used in subjects with highly increased intravascular permeability, colloids may actually leak into the interstitial space, which could worsen edema by pulling fluid from the intravascular compartment [14]. In our second case, third space loss and bleeding were replaced with 12-15 $\mathrm{ml} / \mathrm{kg} / \mathrm{h}$ of crystalloids. However, the intravascular volume was thought to be lacking because of low BP, especially diastolic pressure, normal range of $\mathrm{Hb}(18.7 \mathrm{mg} / \mathrm{dl})$ despite bleeding, and lots of bowel manipulation and oozing. However, the $\mathrm{Hb}$ of a preterm neonate is unpredictable, varying from 14.5 to $21 \mathrm{mg} / \mathrm{dl}$ according to perinatal circumstances [5]. Therefore, it is better to have a $\mathrm{Hb}$ estimation before surgery for reference value.

After the surgery in our second case, laboratory study was performed, which showed PT/aPTT/INR $14.2 \mathrm{sec} / 85.2 \mathrm{sec} / 1.22$ (normal range; 10.4-13.3/23.2-39.4/0.85-1.25), and serum albumin $1.59 \mathrm{~g} / \mathrm{dl}$ (normal range; 3.5-5.0). Therefore, in the NICU, $60 \mathrm{ml}$ of normal saline, $40 \mathrm{ml}$ of FFP, and $13 \mathrm{ml}$ of $20 \%$ albumin were infused during $6 \mathrm{~h}$, which induced generalized edema. Plasma is not indicated for intravascular volume expansion since other components are safer and better for those indications. However, when it is administered, it may act as a colloid, as it contains protein and albumin. There are no practical laboratory studies that definitely indicate the need for FFP in the perioperative period. Rather, its use is guided by clinical evidence of nonsurgical bleeding, a high probability of clotting factor deficiency, or prolonged coagulation time [3]. More than $50 \mathrm{ml}$ of colloid and $60 \mathrm{ml}$ of crystalloid at the postoperative phase to a $2.5 \mathrm{~kg}$ oliguric premature baby seems to be hazardous, since administration of excessive fluid and sodium may increase the risk of chronic lung disease and PDA [10,15]. Intraoperative use of FFP and albumin might lessen crystalloids loading and restore coagulation factors and albumin. However, the decision to administer without laboratory data is very difficult. To gain more than $4 \mathrm{ml}$ of sample to fully draped hypotensive $2.5 \mathrm{~kg}$ infant was unacceptable.

The sign of volume depletion of our first case was tachycardia. Tachycardia may result from both ECF excess and hypo- volemia. Infants maintain cardiac output by increasing HR and may present with a normal BP until relatively late in their progression to uncompensated shock. Therefore, BP alone is a poor index of hemodynamic status although diastolic pressure can be helpful in states of vasodilated preshock [9]. Thus, a significant tachycardia with other signs of decreased perfusion and a cause of fluid loss should be treated aggressively, even with a normal BP [9]. The assessment of fluid deficits cannot be based on measured losses alone as these are very inaccurate. Hemodynamic status must be evaluated including HR, BP, capillary refill, urine output, and, if available, central venous pressure. Dopamine may used if hypotension persists despite seemingly adequate volume resuscitation, especially when there is an intraabdominal process associated with sepsis [3]. However, careful titration should be given to extremely prematures not to make intraventricular hemorrhage, since they have fragile vessels.

Neonates, particularly when premature, show physiologically low GFR and low urinary flow rate on the first day of life [6]. In that period, the infant may be unable to increase water excretion to approximate water intake and may develop edema easily $[5,6]$. Renal maturation appears to be accelerated after 34 weeks of gestation and there is a rapid, almost two-fold increase in the GFR during the first week of life, which continues over the first few months [4]. Low GFR at birth is due to small glomerular capillary area available for filtration, structural immaturity of the glomerular capillaries, low arterial BP, high hematocrit, and renal vasoconstriction, which results in a low glomerular plasma flow [4]. Therefore, we should not regard urine output as a sole guide of hydration. Although delayed micturition in a healthy infant is not of concern until $24 \mathrm{~h}$ after birth, urine output in a critically ill infant should be assessed using urethral catheterization if indicated [15]. When oliguria exists, initial laboratory examination including urinalysis, blood urea nitrogen, creatinine, and fractional excretion of sodium is required. Twenty milliliters per $\mathrm{kg}$ of normal saline can be administered as two infusions at $10 \mathrm{ml} / \mathrm{kg} / \mathrm{h}$ then dopamine and furosemide can be used in that order. Unresponsive to increased cardiac output and diuresis, an abdominal sonography should be performed to define renal, urethral, and bladder anatomy [15].

In conclusion, the magnitude of volume loss of small infant is difficult to measure. Volume depletion may cause acute tubular necrosis, while overloading may induce PDA, which is the cause of many complications of preterms. Therefore, fluid deficits should be assessed and restored tightly by measured losses at present and various hemodynamic parameters. 


\section{References}

1. Kattwinkel J, McGowan JE, Zaichkin J, Aziz K, Colby C, Escobedo M, et al. Neonatal resuscitation. 6th ed. Elk Grove Village, American Academy of Pediatrics and American Heart Association. 2011, pp 1-35.

2. Liu LM. Perioperative fluid management. In: A practice of anesthesia for infants and children. Edited by Ryan JF, Todres ID, Cote CJ, Goudsouzian N: Orlando, Grune \& Stratton. 1986, pp 115-21.

3. Litman RS. Fluid and blood administration. In: Pediatric anesthesia: the requisites in anesthesiology. Edited by Hines RL: Philadelphia, Elsevier Mosby. 2004, pp 115-21.

4. Aperia A, Zetterström R. Renal control of fluid homeostasis in the newborn infant. Clin Perinatol 1982; 9: 523-33.

5. Black A, McEwan A. Paediatric \& neonatal anaesthesia. London, Butterworth Heinemann. 2004, pp 64-73.

6. Ellis D. Regulation of fluids and electrolytes. In: Smith's anesthesia for infants and children. 8th ed. Edited by Davis PJ, Cladis FP, Motoyama EK: Philadelphia, Elsevier. 2011, pp 116-56.

7. Paut O, Lacroix F. Recent developments in the perioperative fluid management for the paediatric patient. Curr Opin Anaesthesiol 2006; 19: 268-77.

8. Murat I, Dubois MC. Perioperative fluid therapy in pediatrics. Paediatr Anaesth 2008; 18: 363-70.

9. Withington DE. Perioperative fluid management. In: Anesthesia intensive care and pain in neonates and children. Edited by Astuto M: Milan, Springer. 2009, pp 135-49.

10. Murat I, Humblot A, Girault L, Piana F. Neonatal fluid management. Best Pract Res Clin Anaesthesiol 2010; 24: 365-74.

11. Niermeyer S. Volume resuscitation: crystalloid versus colloid. Clin Perinatol 2006; 33: 133-40.

12. Oca MJ, Nelson M, Donn SM. Randomized trial of normal saline versus $5 \%$ albumin for the treatment of neonatal hypotension. J Perinatol 2003; 23: 473-6

13. Cochrane Injuries Group Albumin Reviewers. Human albumin administration in critically ill patients: systematic review of randomised controlled trials. BMJ 1998; 317: 235-40.

14. Bailey AG, McNaull PP, Jooste E, Tuchman JB. Perioperative crystalloid and colloid fluid management in children: where are we and how did we get here? Anesth Analg 2010; 110: 375-90.

15. Doherty EG. Fluid and electrolyte management. In: Manual of neonatal care. 7th ed. Edited by Cloherty JP, Eichenwald EC, Hansen AR, Stark AR: Philadelphia, Lippincott Williams \& Wilkins. 2012, pp 269-83. 